Atopic history in patients with the acquired immune deficiency syndrome

\begin{tabular}{|c|c|c|c|c|c|c|c|}
\hline $\begin{array}{l}\text { Case } \\
\text { No }\end{array}$ & $\begin{array}{l}\text { Age and } \\
\text { sex }\end{array}$ & Diagnosis of AIDS & Atopic history & $\begin{array}{l}\text { Age when } \\
\text { symptoms } \\
\text { present (years) }\end{array}$ & $\begin{array}{l}\text { Atopic symptoms } \\
\text { related to } \\
\text { AIDS }\end{array}$ & Temporal relation to AIDS & Family history \\
\hline 1 & $27 M$ & $\begin{array}{l}\text { Kaposi's sarcoma, } \\
\text { Pneumocystis carinii pneumonia }\end{array}$ & Asthma & $8-12$ & $\begin{array}{l}\text { Hay fever, reaction } \\
\text { to cat fur }\end{array}$ & $\begin{array}{l}\text { Occurred with persistent generalised } \\
\text { lymphadenopathy }\end{array}$ & None \\
\hline 2 & $49 \mathrm{~F}$ & P carinii pneumonia & Hay fever & $16-20$ & $\begin{array}{l}\text { Asthma, reaction } \\
\text { to milkt }\end{array}$ & $\begin{array}{l}\text { Asthma developed three years before AIDS; } \\
\text { incubation period of human immunodeficiency } \\
\text { virus was at least five years, suggesting an } \\
\text { association. Reaction to milk developed one } \\
\text { month after AIDS }\end{array}$ & Son and grandmother \\
\hline 3 & $36 M$ & $\begin{array}{l}P \text { carinii pneumonia, oesophageal } \\
\text { candidiasis }\end{array}$ & Asthma & 14 & Eczema, hay fever & $\begin{array}{l}\text { Occurred with persistent generalised } \\
\text { lymphadenopathy }\end{array}$ & Mother \\
\hline 4 & $21 M$ & Mycobacterial pneumonia & Eczema & $2-8$ & Hay fever & $\begin{array}{l}\text { Occurred with persistent generalised } \\
\text { lymphadenopathy }\end{array}$ & None \\
\hline 5 & $36 M$ & Kaposi's sarcoma & $\begin{array}{l}\text { Asthma, hay } \\
\text { fever }\end{array}$ & $5-18,5-10$ & Asthma & Developed three months after AIDS & None \\
\hline 6 & $47 M$ & $\begin{array}{l}\text { Kaposi's sarcoma, } \\
P \text { carinii pneumonia }\end{array}$ & Asthma, eczema & From childhood & Asthma, eczema & $\begin{array}{l}\text { Considerable increase in asthma; eczema developed } \\
\text { with Kaposi's sarcoma }\end{array}$ & Not known \\
\hline 7 & $51 \mathrm{M}$ & $P$ carinii pneumonia & Hay fever & From childhood & No change & & None \\
\hline
\end{tabular}

*Rhinitis, sneezing, and conjunctivitis on exposure.

tSwelling of tongue and lips 5-10 minutes after every exposure to milk.

deficient. They characteristically show defective cell mediated immunity with reduced numbers and function of $T_{4}$ lymphocytes, including decreased production of interleukin 2 and interferon gamma. ${ }^{2}$ Total IgE concentrations were not higher in the atopic patients with AIDS, but the results of prick testing suggest that specific IgE may be increased. The IgE response is regulated by factors derived from $T$ cells and induced by substances, possibly interferons, that are derived from macrophages. ${ }^{3}$

This study provided striking evidence for the in vivo activity of recombinant interferon gamma. Improvement in the atopic symptoms may have been caused by a direct effect of interferon gamma on mediation of the allergic response-for example, by influencing the cellular control of IgE production or by a peripheral effect on mast cell binding of or responsiveness to IgE.

Although an increased incidence of atopic eczema has been noted in children with AIDS, ${ }^{4}$ this is the first documentation of exacerbation of atopy in adults. We have provided evidence that cellular immunity, apparently through interferon gamma, has a role in regulating atopy; this has implications for the pathogenetic mechanisms underlying atopic disease in general.

We thank the patients, without whom this work would not have been possible. The work was supported partly by the Medical Research Counci and partly by Biogen Medical Research.

\section{References}

1 Eales L-J, Moshtael O, Pinching AJ. Microbicidal activity of monocyte derived macrophages in AIDS and related disorders. Clin Exp Imomunol 1986;67:227-35.

2 Pinching AJ, Weiss RA. AIDS and the spectrum of HTLV-IIV/LAV infection. Int Rev Exp Patho 1986;28:1-44.

3 Ishizaka K. Regulation of IgE synthesis. Anmual Revienus of Immunology 1984;2:159-82.

4 Scott GB, Buck BE, Leterman JG, Bloom FL, Parks WP. Acquired immunodeficiency syndrome in infants. N Engl f Med 1984;310:76-81.

(Accepted 28 October 1986)

\title{
Exaggerated postural vasoconstrictor reflex in Raynaud's phenomenon
}

\author{
NIELS OLSEN, OSCAR ULF PETRING, NIELS ROSSING
}

\begin{abstract}
The central and local regulation of capillary blood flow in the finger was studied by the local $x^{-130 n^{-133}}$ washout technique in women with primary Raynaud's phenomenon, men with vibration induced white finger, and their respective sex matched controls. The vasoconstrictor response to venous stasis of $\mathbf{4 0}$ $\mathrm{mm} \mathbf{H g}$ elicited by local reflex was normal in both types of
\end{abstract}

\footnotetext{
Department of Clinical Physiology and Nuclear Medicine and Clinic of Occupational Medicine, Rigshospitalet, University of Copenhagen, Copenhagen, Denmark

NIELS OLSEN, MD

OSCAR ULF PETRING, MD

NIELS ROSSING, MD
}

Correspondence and requests for reprints to: Dr Niels Olsen, Department of Clinical Physiology and Nuclear Medicine, Rigshospitalet, Blegdamsvei 9 DK-2100, Copenhagen $\emptyset$, Denmark.
Raynaud's phenomenon. Change in posture from lying to sitting induced vasoconstriction in all groups, which was abolished by proximal nervous blockade. The vasoconstrictor response to sitting was augmented in both groups of subjects with Raynaud's phenomenon compared with their sex matched controls.

These results show the existence of central and local postural vasoconstrictor reflexes in normal fingers. In both types of Raynaud's phenomenon there was hyperreactivity of the central sympathetic nervous system to orthostatic stress and normal function of digital arterioles and postganglionic sympathetic nerve fibres.

\section{Introduction}

Raynaud's phenomenon is episodes of well demarcated pallor of one or more fingers brought on by cold. Raynaud's original proposal of hyperactivity of the central sympathetic nervous system ${ }^{1}$ and the later assertion by Lewis of a "local digital vascular fault" remain the 
two classic theories of the phenomenon. Raynaud also suggested that emotion could provoke the episodes, whereas Lewis never observed an attack due to a stimulus other than cold. We decided to see whether postural stimuli could induce increased vasoconstrictor responses in the fingers of people with Raynaud's phenomenon. Because of the contradictory theories both a local and a central sympathetic reflex were investigated. The local reflex was elicited by lowering the hand or by venous stasis, ${ }^{3}$ and the central reflex was elicited by changing the body posture from supine to erect. ${ }^{4}$ The vasoconstrictor response to both reflexes was assessed by the relative changes in blood flow as determined by the local xenon ${ }^{-133}$ washout technique ${ }^{5}$ in women with primary Raynaud's phenomenon and men with vibration induced white finger. The results were compared with those in sex matched controls.

\section{Subjects and methods}

The study groups comprised seven women with primary Raynaud's phenomenon and 10 sex matched controls, and seven men with vibration white finger and eight sex matched controls. All subjects gave informed consent to the study, which was approved by the local ethical committee. The men with vibration white finger had been diagnosed in the hospital's clinic of occupational medicine. Most other subjects were medical students. Subjects were selected according to the following criteria: age 21-49; healthy except for Raynaud's phenomenon; no abuse of aicohol; not receiving medicines; no history of digital gangrene; controls and subjects with primary Raynaud's phenomenon never worked with vibrating hand tools; and primary Raynaud's phenomenon and vibration white finger diagnosed according to the criteria of Allen and Brown ${ }^{6}$ and Taylor and Pelmear. ${ }^{7}$ The severity of Raynaud's phenomenon was assessed according to a modified Taylor-Pelmear scale': stage 1, blanching of one or more fingertips; stage 2, blanching of one or more fingers; stage 3, extensive blanching of most fingers with frequent episodes in summer and winter.

Table I gives details of the four groups of subjects. Both groups with

TABLE I-Data on seven men with vibration induced white finger and eight male controls, and seven women with primary Raynaud's phenomenon and 10 female controls. Mean arterial blood pressure recorded on upper arm and systolic pressure gradient recorded from upper arm to finger (both values recorded at rest). Stage of vibration white finger and primary Raynaud's phenomenon refers to modified TaylorPelmear scale evaluating severity of disorders. Values are medians (ranges in parentheses)

\begin{tabular}{|c|c|c|c|c|}
\hline & $\begin{array}{c}\text { Vibration } \\
\text { white } \\
\text { finger } \\
(n=7)\end{array}$ & $\begin{array}{c}\text { Controls } \\
(\text { men) } \\
(\mathbf{n}=8)\end{array}$ & $\begin{array}{c}\text { Primary } \\
\text { Raynaud's } \\
\text { phenomenon } \\
(\mathbf{n}=7)\end{array}$ & $\begin{array}{c}\text { Controls } \\
\text { (women) } \\
(n=10)\end{array}$ \\
\hline $\begin{array}{l}\text { Age (years) } \\
\text { Stage of vibration white finger and } \\
\text { primary Raynaud's phenomenon } \\
\text { No of affected fingers } \\
\text { Duration of vibration white finger and } \\
\text { primary Raynaud's phenomenon } \\
\text { (years) } \\
\text { Duration of exposure to vibration } \\
\text { (years) } \\
\text { Latent period of vibration white finger } \\
\text { (years) } \\
\text { Mean arterial blood pressure }(\mathrm{mm} \mathrm{Hg} \text { ) } \\
\text { Systolic pressure gradient (mm Hg) }\end{array}$ & $\begin{array}{c}9(3-19) \\
15(12-21) \\
8(2-20) \\
93(87-100) \\
5(0-15)\end{array}$ & $\begin{array}{l}89(82-95) \\
10(0-20)\end{array}$ & $\begin{array}{l}32(22-39)^{\star} \\
2(1-3) \\
8(6-10)\end{array}$ & $\begin{array}{l}88(72-100) \\
10(0-15)\end{array}$ \\
\hline
\end{tabular}

ॠ Significantly different from sex matched controls $(p<0.05)$.

Raynaud's phenomenon were older than their sex matched controls. Four subsamples were selected as follows to see if the results could be explained by the age differences: the four youngest men with vibration white finger and their four controls, and the four youngest women with primary Raynaud's phenomenon and their four oldest controls. In these subsamples age did not differ significantly between men with vibration white finger and their controls $(p>0 \cdot 1)$ or between women with primary Raynaud's phenomenon and their controls $(p>0 \cdot 1)$.

All subjects had abstained from tobacco, alcohol, and work with vibrating tools for at least three hours before the study. They were studied at a room temperature of $24.0 \pm 0.5^{\circ} \mathrm{C}$ after at least 45 minutes' rest and when feeling comfortably warm without sweating. None had ischaemic or atrophic fingers. The most severely affected fingers were tested. In four men with vibration white finger the central reflex was also examined in a non-affected finger. In the controls the same fingers (second to fourth) were used as in subjects with Raynaud's phenomenon. In all subjects a normal blood pressure was measured on the arm by auscultations using a $12 \mathrm{~cm}$ cuff. Mean arterial blood pressure was estimated as diastolic pressure plus one third of the pulse pressure (table I). Finger systolic blood pressure was measured by strain gauge plethysmography, ${ }^{8}$ the systolic pressure gradient from arm to finger being $20 \mathrm{~mm} \mathrm{Hg}$ or less in all subjects (table I). It was therefore assumed that all subjects with Raynaud's phenomenon had clear vasospastic disease without a definite obstructive element.9

Vasoconstrictor reflexes were assessed by measuring the relative change in skin capillary blood flow. This was determined from the difference in washout rate of a cutaneous ${ }^{133} \mathrm{Xe}$ depot before, during, and after the study stimulus. The site of radioactive skin labelling was the dorsum of the distal interphalangeal joint, where there are no arteriovenous anastomoses. ${ }^{10} \mathrm{~A}$

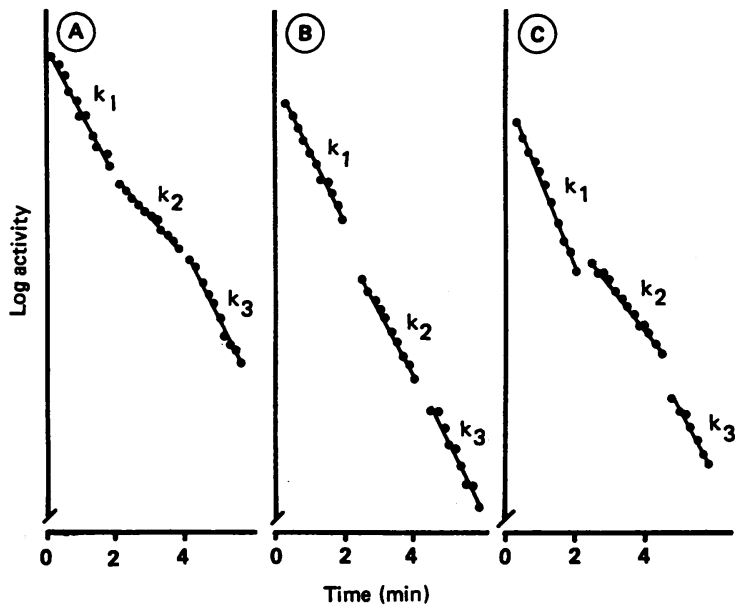

Examples of ${ }^{133} \mathrm{Xe}$ washout curves with rate constant before $\left(k_{1}\right)$, during $\left(k_{2}\right)$, and after $\left(k_{3}\right)$ applied test. Change factor. $F$ calculated as: $F=k_{2} /\left(0.5 \times\left(k_{1}+k_{3}\right)\right)$. (A) Venous stasis of $40 \mathrm{~mm} \mathrm{Hg}$ in man with vibration induced white finger $(F=0 \cdot 55$ ). (B) Sitting upright in female control $(F=0 \cdot 93)$. (C) Sitting upright in woman with primary Raynaud's phenomenon $(F=0.57)$.

skin area of $12 \mathrm{~mm}$ diameter was labelled with ${ }^{133} \mathrm{Xe}$ in isotonic solution ( 370 $\mathrm{MBq} / \mathrm{ml}$ ) over two minutes by a modified atraumatic labelling technique. ${ }^{11}$ The disappearance of radioactivity from the labelled area was monitored externally from one minute after labelling with a sodium iodide scintillation detector with the crystal surface $9 \mathrm{~cm}$ above the skin and wide collimation. The disappearance curve, corrected for background activity, was plotted against time in semilogarithmic scale.

The local reflex was investigated with the subjects lying supine with the finger at the midaxillary line. The forearm and hand were immobilised in a plaster splint. Venous stasis of $40 \mathrm{~mm} \mathrm{Hg}$ was produced by a cuff placed on the upper arm. ${ }^{3}$ The washout rate of one depot was measured $(a)$ with the cuff deflated, (b) with the cuff inflated to $40 \mathrm{~mm} \mathrm{Hg}$, and $(c)$ with the cuff deflated again. Each period of measurements lasted about two minutes.

The central reflex was investigated by repeating the labelling and measuring the count rates with the subjects $(a)$ lying supine, $(b)$ sitting on a chair with a straight back, and $(c)$ lying supine. Each period lasted about two minutes. The finger was kept at the level of the jugular notch in all three periods. During each period pulse rate and arm blood pressure were measured on the contralateral arm. In one woman with primary Raynaud's phenomenon and a woman control the response to sitting was also measured during conventional nerve block of the finger after repeated labelling. Blockade was performed by applying $4 \mathrm{ml} 2 \%$ lignocaine at the base of the finger and considered to be effective when perception was lost to pinprick and temperature. The measurement started once the finger systolic pressure had returned to normal.

A control experiment was performed during steady state conditions in seven subjects to ascertain that the undisturbed washout rate during the initial six to seven minutes was monoexponential. ${ }^{3}$

In both tests the washout rate constant $(/ \mathrm{min})$ was defined as (a) the slope of the radioactivity disappearance curve $\left(k_{1}\right)$ in the first reference period before the stimulus, $(b)$ the slope $\left(k_{2}\right)$ in the test period, and $(c)$ the steepest slope $\left(k_{3}\right)$ in the second reference period after the stimulus. Rate constants were computed from the regression line calculated from the least square method. Slowing of the washout during vasoconstriction was described 
numerically by the change factor " $F$," defined as: $F=k_{2} /\left(0.5 \times\left(k_{1}+k_{3}\right)\right) .^{3}$ The figure gives examples of washout curves.

The difference in numerical values between men with vibration white finger and their controls and between women with primary Raynaud's phenomenon and their controls was tested with the Mann-Whitney rank sum test. The difference in numerical values within a group was tested with the Wilcoxon matched pairs signed rank test. The correlation between change factor $\mathrm{F}$ and age was tested with the Spearman rank correlation coefficient $\left(r_{s}\right)$ in each of the four groups. In the two subjects with an applied nerve block the standard deviation (SD) of an $F$ value was calculated from the standard deviations of the washout rate constants-that is, $\operatorname{SD}\left(k_{1}\right)$, $\mathrm{SD}\left(\mathrm{k}_{2}\right), \mathrm{SD}\left(\mathrm{k}_{3}\right)$ - using the formula:

$$
\mathrm{SD}(\mathrm{F})=\mathrm{F} \times \sqrt{\left(\mathrm{SD}^{2}\left(\mathrm{k}_{2}\right) / \mathrm{k}_{2}^{2}\right)+\left[\left(\mathrm{SD}^{2}\left(\mathrm{k}_{1}\right)+\mathrm{SD}^{2}\left(\mathrm{k}_{3}\right)\right) /\left(\left(\mathrm{k}_{1}+\mathrm{k}_{3}\right)^{2}\right)\right]} .
$$

The difference between two $F$ values in each of these subjects was tested against the null hypothesis.

A significance limit of 0.05 (two tailed) was used in all statistical tests. Results are given as medians and ranges or as means and 1 SD unless stated otherwise.

\section{Results}

Mean pulse rate increased by 5 (1 SEM 1 ) beats/min in the sitting versus supine positions $(n=32 ; p<0.05)$ with no significant differences between groups of men $(p>0.05)$ and groups of women $(p>0 \cdot 1)$. Correspondingly mean arterial blood pressure increased by 1.2 (1 SEM 0.6) $\mathrm{mm} \mathrm{Hg}(n=32$; $p>0.05)$ with no difference between sex matched groups $(p>0.1)$.

In the control steady state experiments $F$ was $1 \cdot 00(0.93-1 \cdot 10)$ and thus not different from unity $(p>0 \cdot 1)$. Hence a monoexponential washout rate during constant blood flow $^{3}$ was confirmed. Table II shows the relative changes in cutaneous blood flow during venous stasis and sitting in the four groups expressed as change factor $(F)$ values. The decrease in blood flow in

TABLE II-Responses to venous stasis of $40 \mathrm{~mm} \mathrm{Hg}$ and change in body posture from supine to sitting in four groups of subjects, expressed as relative change in ${ }^{133} \mathrm{Xe}$ washout rate constant $(F)$. Values are medians (ranges in parentheses).

\begin{tabular}{lll}
\hline Group & \multicolumn{1}{c}{ Venous stasis } & \multicolumn{1}{c}{ Sitting } \\
\hline Vibration white finger $(n=7)$ & $0.54(0.42-0.59) \dagger$ & $0.55(0.46-0.62)^{\star \star}$ \\
Controls (men) $(n=8)$ & $0 \cdot 49(0 \cdot 40-0.61)$ & $0.90(0 \cdot 82-0.95)$ \\
Primary Raynaud's phenomenon $(n=7)$ & $0.49(0.40-0.63) \dagger$ & $0.51(0.43-0.61)^{\star \star}$ \\
Controls (women) $(n=10)$ & $0.52(0.40-0.64)$ & $0.76(0.70-0.95)$
\end{tabular}

F Significantly different from unity in all cases $(\mathrm{p} \leqq 0 \cdot 02)$.

$\star \star$ Significantly different from sex matched controls in same test $(p<0.01)$.

+ Not significantly different from sex matched controls in same test $(p>0 \cdot 1)$.

response to venous stasis showed no significant difference between subjects with the Raynaud's phenomenon and their sex matched controls. By contrast, the decrease in response to change in body posture was significantly greater in the subjects with vibration white finger and primary Raynaud's phenomenon than in their respective controls. Furthermore, in the nonaffected fingers of four subjects with vibration white finger blood flow decreased during sitting to an $F$ value of $0.54(0.48-0.55)$. This was significantly different from the values found in the male controls $(p<0.01)$. Nerve block inhibited the vasoconstrictor response to sitting in both women examined. Without blockade sitting induced an $F$ value of 0.51 (I SD 0.04) in the subject with primary Raynaud's phenomenon and 0.74 (0.06) in the control. With blockade the values rose to 0.99 (1 SD 0.10; $<<0.0001)$ and $0.97(0.07 ; \mathrm{p}<0.01)$, respectively.

In neither test were changes in blood flow significantly correlated with age in any of the four groups $(p>0 \cdot 1)$. In the age matched subsamples the response to venous stasis did not differ significantly between sex matched groups $(p>0 \cdot 1)$, whereas the response to sitting yielded a significantly smaller $F$ value in both groups with Raynaud's phenomenon than in their sex matched controls $(p<0 \cdot 05)$. Thus there was no evidence that the results in table II could be explained by age.

\section{Discussion}

In this as in other studies the local vasoconstrictor reflex, elicited by venous stasis, was shown in the normal finger. ${ }^{12} 13 \mathrm{~A}$ small but consistent response during sitting was measured in the normal finger, and the response was abolished by a proximal nerve block. This suggests that the central postural reflex, which has been shown in the forearm, ${ }^{4}$ also exists in the normal finger.

Our findings show that the fingers of subjects with primars Raynaud's phenomenon and vibration white finger have a norma\$ vasoconstrictor response to venous stasis and an augmentedresponse to change in body posture. Theoretically this augmente response might be due to one or more of the following mechanisms hyperactivity of the central sympathetic nervous system; post ganglionic exaggerated transmission of normal central nerve impulses; augmented arteriolar response to a normal sympathetio stimulus. In our study, however, the local reflex functioned without: any overshoot in subjects with Raynaud's phenomenon. Thus ther $\overline{\overline{\overrightarrow{5}}}$ was no evidence of hyperreactivity of the arterioles or peripherat sympathetic nerve fibres. The results may be explained exclusivel by hyperactivity of the central sympathetic nervous system in the subjects with Raynaud's phenomenon, and the finding of an augmented response during sitting in non-affected fingers of

If hypertrophy of arteriolar smooth muscle cells explained thẹ exaggerated response to cold in subjects with vibration whit $\vec{e}$ finger ${ }^{14}$ we s' Juld expect an augmented response to venous stasis, a. in essential hypertension. ${ }^{15}$ But our subjects with Raynaud's phenomenon s'tor ed a normal local reflex and thus muscula?. hypertrophy oi t ie arterioles was not detected. Subjects witho vibration white finger may suffer from peripheral neuropathy. This might abolish the local reflex, as found in patients with diabetis orthostatic hypotension. ${ }^{17} \mathrm{We}$, however, found no dysfunction of the peripheral sympathetic nerve fibres in the subjects with Raynaud's phenomenon, as they had normal function of the locab reflex. In contrast with our results in vasospastic types of Raynaud's phenomenon, the local reflex is absent in patients with generalisedo scleroderma, ${ }^{13}$ who often suffer from an obstructive type of Raynaud's phenomenon.

Our results seem to accord with Raynaud's suggestion of hyperactivity of the central sympathetic nervous system in subjectso with vasospastic types of the phenomenon. ${ }^{1}$ This hyperactivity may be of constitutional origin in subjects with primary Raynaud'o phenomenon and may be induced by prolonged usage of vibrating hand tools in subjects with vibration white finger.

This investigation was supported by the Health Insurance Society and the University of Copenhagen.

\section{References}

1 Raynaud M. De l'asphyxie locale et de la gangrene symetrique des extrémités. Paris: Rignoux, 1862.

Lewis $\mathrm{T}$. Experiments relating to peripheral mechanism involved in spasmodic arrest of the circulation in the fingers. A variety of Raynaud's disease. Hean 1929;15:7-101.

3 Henriksen O, Sejrsen P. Local reflex in microcirculation in human cutaneous tissue. Acta Physion Scand 1976;98:227-31.

4 Skagen K, Bonde-Petersen F. Regulation of subcutaneous blood flow during head-up tilt $\left(45^{\circ}\right)$ in

normals. Acta Physiol Scand 1982;31:31-5.
5 Sejrsen P. Blood flow in cutaneous tissue in man studied by washout of radioactive xenon. Circ Res 1969;25:215-29.

6 Allen EV, Brown GE. Raynaud's disease: a critical review of minimal requisites for diagnosis. Am f Med Sci 1932;183:187-200.

7 Taylor W, Pelmear PL. Vibration white finger in industry. London: Academic Press, xvii-xxii. 8 Hirai M, Nielsen SL, Lassen NA. Blood pressure measurement of all five fingers by strain gauge plethysmography. Stand F Clin Lab Invest 1976;36:627-32. 9 Hirai MH. Arterial insufficiency of the hand evaluated by digital blood pressure and arteriof
graphic findings. Circulation 1978;58:902-8.

10 Grant RT, Bland EF. Observations on arteriovenous anastomoses in human skin and in the bird'D foot with special reference to reaction to cold. Heart 1929-31;15:385-411.

11 Sejrsen P. Atraumatic local labeling of skin by inert gas: epicutaneous application of xenon $13 \frac{6}{2}$ f Appl Physiol 1968;24:570-2.

12 Gaskell P, Burton AC. Local postural vasomotor reflexes arising from the limb veins. Circ Re 1953;1:27-39.

13 Kristensen JK. Local regulation of digital blood flow in generalized scleroderma. $\mathcal{F}$ Invest Dermatot 1979;72:235-40.

14 Hyvärinen J, Pyykkö I, Sundberg S. Vibration frequencies and amplitudes in the etiology of traumatic vasospastic disease. Lancet 1973;i:791-4.

15 Henriksen O, Skagen K, Amtorp O, Hartling O. Augmented vasoconstrictor response to change in vascular transmural pressure in patients with essential arterial hypertension. Acta Physio Scand 1981;112:323-9. 16 Seppälainen AM. Peripheral neuropathy in forest workers. A field study. Work, Environment
Health 1972;9:106-11. 17 Hilsted J. Decreased sympathetic vasomotor tone in diabetic orthostatic hypotension. Diabetes
$1979 ; 28: 970-3$.

(Accepted 17 February 1987)

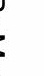

